PEDIATRIC NEUROLOGY BRIEFS

A MONTHLY JOURNAL REVIEW

J. GORDON MILLICHAP, M.D., F.R.C.P., EDITOR

Vol. 5, No. 6

June 1991

\title{
NEUROCUTANEOUS SYNDRONES
}

LISCH NODULES IN NEUROFIBROMATOSIS TYPE 1

The prevalence of Lisch nodules among 167 patients with neurofibromatosis 1 is reported from the Department of Pediatrics, Genetics Division, Miami Children's Hospital, Miama, FL. Lisch nodules are dome-shaped hamartomatous lesions with a clear, yellow or brown appearance. The overall prevalence of $\mathrm{Lisch}$ nodules was $73.7 \%$ and similar to that of neurofibromas $(68.3 \%)$. The prevalence varied directly with the age of the patients: $5 \%$ in children less than 3 years of age, $42 \%$ in those 3 to 4 years old, $55 \%$ at 5 to 6 years; and $100 \%$ in adults of 21 years of age or older. Lisch nodules appeared more frequently than neurofibromas in all but the youngest age group. Of 145 patients having radiological studies, 17 had optic gliomas (12\%), 9 had other types of CNS tumor, and one had both optic glioma and another CNS tumor. The proportion of Lisch nodules was similar in those with or without CNS tumors. If $\mathrm{Lisch}$ nodules do not appear with increasing age, the risk of having the gene for neurofibromatosis 1 is recuced from $50 \%$ at birth to $31 \%$ at 5 to 6 years of age, $15 \%$ at 9 to 14 years of age, $8 \%$ at 15 to 20 years of age, and $0 \%$ in those over the age of 20. (Lubs MLE, Bauer MS et al. Lisch nodules in neurofibromatosis type 1. N Engl J Med May 2, 1991; 324:1264-1266).

OOMMENT. Multiple Lisch nodules, unlike cafe-au-lait spots and neurofibromas, are specific for the diagnosis of neurofibromatosis 1. Except for one case they have been absent in central neurofibromatosis 2. Iisch nodules are useful in the early diagnosis of neurofibromatosis 1 and slit-lamp examination is important in suspected cases.

PEDIATRIC NEUROLOGY BRIEFS (ISSN 1043-3155) @1991 covers selected articles from the world literature and is published monthly. Subscrip$t$ ion requests ( $\$ 33$ US or $\not 18$ UK annually; add $\$ 8$ ( $\not 4)$ for airmail outside North America) may be sent to: Pediatric Neurology Briefs J. Gordon Millichap, M.D., F.R.C.P. - Editor, P.O. Box 11391, Cicago, IL 60611, USA, or Nat Wst Bnk, 94 Kensington High Street, London W8, UK. The Editor is Professor Fmeritus at Northwestern University Medical School, Chicago, and is presently at Southern Illinois University School of Medicine, Springfield, Illinois, USA. 